EGU21-16296, updated on 05 Apr 2021

https://doi.org/10.5194/egusphere-egu21-16296

EGU General Assembly 2021

(c) Author(s) 2021. This work is distributed under

the Creative Commons Attribution 4.0 License.

\title{
Regional calibration and electromagnetic conductivity imaging for assessing the dynamics of soil salinity
}

\author{
Maria Catarina Paz ${ }^{1,2}$, Mohammad Farzamiann ${ }^{2,3}$, Ana Marta Paz ${ }^{3}$, Nádia Luísa Castanheira ${ }^{3}$, Maria \\ Conceição Gonçalves ${ }^{3}$, and Fernando Monteiro Santos ${ }^{2}$ \\ ${ }^{1}$ Polytechnic Institute of Setúbal, Barreiro School of Technology, CIQuiBio, Lisbon, Portugal (catarina.paz@gmail.com) \\ ${ }^{2}$ Instituto Dom Luiz, Faculdade de Ciências da Universidade de Lisboa, Campo Grande, Edifício C1, Piso 1, $1749-016$ Lisboa, \\ Portugal \\ ${ }^{3}$ Instituto Nacional de Investigação Agrária e Veterinária, Avenida da República, Quinta do Marquês (edifício sede), \\ 2780-157 Oeiras, Portugal
}

Electromagnetic conductivity imaging $(\mathrm{EMCl})$ is a state-of-the-art methodology for soil salinity assessment over large areas. It involves the following rationale: (1) use of the electromagnetic induction (EMI) geophysical technique to measure the soil apparent electrical conductivity $\left(E_{a}\right.$, $\mathrm{mS} \mathrm{m}^{-1}$ ) over an area; (2) inversion of $\mathrm{EC}_{\mathrm{a}}$ to obtain $\mathrm{EMCl}$, which provides the spatial distribution of the soil electrical conductivity $\left(\sigma, \mathrm{mS} \mathrm{m}^{-1}\right)$; (3) calibration process consisting of a regression between $\sigma$ and the electrical conductivity of the saturated soil paste extract $\left(\mathrm{EC}_{\mathrm{e}}, \mathrm{dS} \mathrm{m}^{-1}\right)$, used as a proxy for soil salinity; and (4) conversion of $\mathrm{EMCl}$ into salinity maps using the obtained calibration equation.

In this study, we applied EMCI and a regional calibration in Lezíria Grande de Vila Franca de Xira, located in Portugal. The study area is an important agricultural system where soil faces the risk of salinization due to climate change, as the level and salinity of groundwater are likely to increase as a result of the rise of the sea water level and consequently of the estuary. These changes can also affect the salinity of the irrigation water which is collected upstream of the estuary.

EMI surveys and soil sampling were carried out between May 2017 and October 2018 at four locations with different salinity levels across the study area. A regional calibration was developed and its ability to predict $\mathrm{EC}_{\mathrm{e}}$ from $\mathrm{EMCl}$ was evaluated. The validation analysis showed that $\mathrm{EC}_{\mathrm{e}}$ was predicted with a root mean square error of $3.14 \mathrm{dS} \mathrm{m}^{-1}$ in a range of $52.35 \mathrm{dS} \mathrm{m}^{-1}$, slightly overestimated $\left(-1.23 \mathrm{dS} \mathrm{m}^{-1}\right)$, with a strong Lin's concordance correlation coefficient of 0.94 and high linearity between measured and predicted data $\left(R^{2}=0.88\right)$. It was also observed that the prediction ability of the regional calibration is more influenced by spatial variability of data than temporal variability of data.

Because of the transient nature of data, it was also possible to perform a preliminary qualitative analysis of soil salinity dynamics in the study area, revealing salinity fluctuations related to the input of salts and water either through irrigation, precipitation, or level and salinity of groundwater. 
